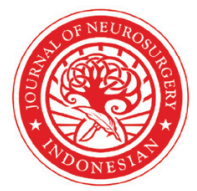

Indonesian Journal of Neurosurgery

\section{High body mass index and high body fat percentage increase risk of meningioma among menopausal women}

\author{
Christian Permana ${ }^{1 *}$, Roland Sidabutar ${ }^{1}$, Selfy Oswari ${ }^{1}$
}

'Department of Neurosurgery, Faculty of Medicine, Universitas Padjadjaran, Dr. Hasan Sadikin Hospital, Bandung, Indonesia

\footnotetext{
*Corresponding to:

Christian Permana; Department of Neurosurgery, Faculty of Medicine, Universitas Padjadjaran - Dr. Hasan Sadikin Hospital, Jl.Pasteur No. 39, 40161, Bandung, West Java, Indonesia; christian.permana.cp@gmail.com
}

\section{Received: 2020-06-07}

Accepted: 2021-05-13

Published: 2021-08-01

\section{ABSTRACT}

Background: Meningiomas are the most common primary brain tumors. One known risk factor for meningioma is exposure to estrogen hormone. Body mass index (BMI) and high body fat percentage have been found to be associated with increased production of estrogen hormone particularly among menopausal women. This study was conducted to determine the effect of BMI and body fat percentage with increased risk of meningioma in menopausal women.

Methods: This was a cross-sectional study which selected its subject using consecutive non-probability sampling method at Neurosurgery Department of Dr. Hasan Sadikin Hospital Bandung from December 2018 to November 2019. A total of 50 subjects were categorized into two groups, the menopausal and premenopausal groups consisting of 25 subjects each. Results: Menopausal women whose BMI was above the normal reference range had a 2.95 times greater risk of suffering from meningioma compared to those with normal BMI, and 1.312 times greater risk ( $95 \%$ Cl 0.934-1.84) when compared to premenopausal women having higher-than-normal BMI. High body fat percentage in menopausal women was found to increase the risk of developing meningioma for up to 2.49 times compared with those with normal body fat percentage and had 1.36-time greater risk ( $95 \%$ Cl 0.901 - 2.051) compared to premenopausal women with normal body percentage.

Conclusion: Menopausal women with higher BMl and body fat percentage were at increased risk of developing meningioma for up to 1.3 times compared to premenopausal women with higher BMI and body fat percentage and nearly 2.5 - 3 times higher risk compared to menopausal women with normal BMI and body fat percentage.

Keywords: body mass index, body fat percentage, menopause, meningioma

Cite This Article: Permana C., Sidabutar, R., Oswari, S. 2021. High body mass index and high body fat percentage increase risk of meningioma among menopausal women. Indonesian Journal of Neurosurgery 4(2): 52-55. DOI: 10.15562/ijn.v4i1.136

\section{INTRODUCTION}

Increased body mass index (BMI) and obesity are recently considered as global health problems, with the prevalence of obesity showing an increasing trend in both developed and developing countries. ${ }^{1,2}$ Increased BMI is a risk factor for various non-communicable diseases, such as diabetes, hypertension, coronary heart disease, and various types of cancer including breast, endometrial, colon and kidney cancer. Higher BMI is also thought to be one of the risk factors of meningioma. ${ }^{3,4}$ Whereas several recent prospective cohort studies suggested a positive association of BMI with meningioma risk. ${ }^{5-8} \mathrm{BMI}$ is closely correlated with body fat mass and adipose tissue is highly endocrine active. Higher body fat volume has been associated with higher levels of estrogen, androgens and insulin-like growth factor. ${ }^{3}$
The relationship between hormonal status and meningioma risk is supported by studies demonstrating higher incidence rates of meningioma in women as compared to men (2: 1); the discovery of estrogen, progesterone and androgen receptors in meningiomas; an association between breast cancer and meningiomas; indications that meningiomas change in size during the luteal phase of the menstrual cycle and pregnancy; and in vitro proliferation of meningioma-cell lines in culture after exposure to estrogen has been observed. ${ }^{9-11}$

In premenopausal women, the ovaries are the main producers of estradiol. However, in menopausal women, the ovaries no longer produce estrogen, and hence the primary production of estrogen is carried out by extragonadal organs such as mesenchymal cells in adipose tissue and the brain. This extragonadal-produced estrogen is locally active and enters the blood circulation. ${ }^{12,13}$ For postmenopausal women, estrogen levels increase with increasing BMI, presumably because conversion of androgens to estrogen in adipose tissue is a primary source of estrogen. ${ }^{14}$

According to the current theories, BMI and body fat percentage are thought to increase the risk of meningioma among women in their menopausal period. This study was conducted to determine the effect of BMI and body fat percentage with increased risk of meningioma in menopausal women.

\section{METHODS}

This was a cross-sectional study which selected its subjects using consecutive non-probability sampling method that included all meningioma patients attending our outpatient clinic or those 
who were managed under Neurosurgery Department of Dr. Hasan Sadikin Hospital Bandung from December 2018 to November 2019 who met the inclusion criteria. Samples collection was performed until the minimum required number of samples was achieved. The sample size was predetermined using a specified formula for correlative analytical study that resulted in a minimum of 25 samples for each group. The inclusion criteria for this study included 1) female sex, 2) confirmed meningioma diagnosis established based on clinical history, physical examination, head CT and/or MRI with contrast and histopathological results. As for exclusion, we specified the following criteria: 1) patients receiving hormonal therapy, 2) patients with a history of brain tumors other than meningioma, 3) patients with sellar meningioma, 4) patients with tumors or malignancies affecting the ovaries.

A total of 50 subjects were divided into two groups, namely the premenopausal and menopausal groups of which each consisted of 25 subjects. The subject was considered menopause only if she did not have any episode of menstrual cycle for more than 12 consecutive months. All the subjects had their BMI calculated according to their anthropometric measurement (weight and height) and were subsequently grouped based on WHO BMI classification for AsianPacific population. A body composition assessment were performed using Omron brand model HBF-306 bioelectrical impedance analysis (BIA) to calculate body fat percentage of which the results were categorized based on the American Council of Exercise (ACE) classification. Diagnosis of meningioma was made based on the findings on contrast-enhanced head computed tomography (CT scan) and/or magnetic resonance imaging (MRI) and histopathological result.

\section{RESULTS}

This study included a total of 50 subjects who were further divided into two groups, namely the premenopausal and menopausal groups, each consisting of 25 subjects. We collected baseline characteristics of the study population which included age, tumor location, histopathological results and $\mathrm{WHO}$ classification. The characteristic of sample can be seen in Table 1 .

Subjects in the menopausal group had an average age of 52 years old whereas an average of 37 years old was found in the premenopausal counterpart. In regard to the three most common locations of meningioma, in the menopausal group, we found 5 (20\%) patients with cavernous meningioma, 5 (20\%) patients with spheno-orbital meningioma, and $5(20 \%)$ patients with convexity meningioma. In the premenopausal group, 6 (24\%) patients had meningioma lesion located in spheno-orbital region, 5 (20\%) patients in convexity region, and 4 (16\%) patients in the parasagittal region. Histopathological studies showed similar characteristics between the two groups for the three most common histopathological subtypes, namely meningothelial meningioma in 11 (44\%) patients in the menopausal group and $13(52 \%)$ patients in the premenopausal group, transitional

\section{Table 1. Characteristic of sample}

\begin{tabular}{|c|c|c|c|c|}
\hline \multirow{2}{*}{ Variable } & \multicolumn{2}{|c|}{ Menopause } & \multicolumn{2}{|c|}{ Premenopausal } \\
\hline & $n$ & $\%$ & $n$ & $\%$ \\
\hline \multicolumn{5}{|l|}{ Age (year) } \\
\hline Mean \pm SD & \multicolumn{2}{|c|}{$52 \pm 5$} & \multicolumn{2}{|c|}{$37 \pm 5$} \\
\hline \multicolumn{5}{|l|}{ Tumor location } \\
\hline Cavernous & 5 & 20 & 2 & 8 \\
\hline Sphenoorbital & 5 & 20 & 6 & 24 \\
\hline Convexity & 5 & 20 & 5 & 20 \\
\hline Sphenoid wing & 3 & 12 & 3 & 12 \\
\hline Cerebellopontine angle & 2 & 8 & 0 & 0 \\
\hline Falx & 2 & 8 & 1 & 4 \\
\hline Parasagittal & 1 & 4 & 4 & 16 \\
\hline Planum sphenoidale & 1 & 4 & 2 & 8 \\
\hline Petroclival & 1 & 4 & 0 & 0 \\
\hline Olfactory groove & 0 & 0 & 1 & 4 \\
\hline Tentorial & 0 & 0 & 1 & 4 \\
\hline \multicolumn{5}{|l|}{ Histopathology result } \\
\hline Meningothelial meningioma & 11 & 44 & 13 & 52 \\
\hline Transitional meningioma & 5 & 20 & 7 & 28 \\
\hline Fibrous meningioma & 4 & 16 & 3 & 12 \\
\hline Angiomatous meningioma & 2 & 8 & 0 & 0 \\
\hline Microcytic meningioma & 0 & 0 & 1 & 4 \\
\hline Atypical meningioma & 2 & 8 & 0 & 0 \\
\hline Clear cell meningioma & 0 & 0 & 1 & 4 \\
\hline Anaplastic meningioma & 1 & 4 & 0 & 0 \\
\hline \multicolumn{5}{|l|}{ WHO classifications } \\
\hline Grade I & 22 & 88 & 24 & 96 \\
\hline Grade II & 2 & 8 & 1 & 4 \\
\hline Grade III & 1 & 4 & 0 & 0 \\
\hline \multicolumn{5}{|l|}{ Body mass index } \\
\hline Underweight $(<18.5)$ & 0 & 0 & 0 & 0 \\
\hline Normal (18.5 - 22.9) & 4 & 16 & 9 & 36 \\
\hline Overweight (23 - 24.9) & 4 & 16 & 9 & 36 \\
\hline Obese $1(25-29.9)$ & 13 & 52 & 7 & 28 \\
\hline Obese $2(\geq 30)$ & 4 & 16 & 0 & 0 \\
\hline \multicolumn{5}{|l|}{ Body fat percentage } \\
\hline Essential fat (10 - $13.9 \%)$ & 0 & 0 & 0 & 0 \\
\hline Athletes $(14-20.9 \%)$ & 0 & 0 & 0 & 0 \\
\hline Fitness $(21-24.9 \%)$ & 1 & 4 & 1 & 4 \\
\hline Average $(25-31.9 \%)$ & 5 & 20 & 10 & 40 \\
\hline Obese $(\geq 32 \%)$ & 19 & 76 & 14 & 56 \\
\hline Total cases & 25 & 100 & 25 & 100 \\
\hline
\end{tabular}


Table 2. Bivariate analysis of body mass index and menopausal status

\begin{tabular}{|c|c|c|c|c|c|}
\hline & \multicolumn{3}{|c|}{ BMI } & \multirow[b]{2}{*}{ POR } & \multirow[b]{2}{*}{ PR (CI) } \\
\hline & $\begin{array}{l}\text { Overweight/ } \\
\text { Obese }\end{array}$ & Normal & $\mathbf{N}$ & & \\
\hline Menopause & 21 & 4 & 25 & \multirow{2}{*}{2.95} & \multirow{2}{*}{$1.312(0.934-1.84)$} \\
\hline Premenopausal & 16 & 9 & 25 & & \\
\hline
\end{tabular}

Table 3. Bivariate analysis of body fat percentage and menopausal status

\begin{tabular}{ccccccc} 
& \multicolumn{3}{c}{ Body fat percentage } & \multirow{2}{*}{ POR } & PR (CI) \\
\cline { 2 - 4 } & Obese & Fitness/Average & N & & \\
Menopause & 19 & 6 & 25 & 2.49 & $1.36(0.901-2.051)$ \\
Premenopausal & 14 & 11 & 25 & & \\
\hline
\end{tabular}

meningioma in $5(20 \%)$ patients in the menopausal group and 7 (28\%) patients in the premenopausal group, fibrous meningioma in $4(16 \%)$ patients in the menopausal group and $3(12 \%)$ patients in the premenopausal group. According to histopathological classification proposed by $\mathrm{WHO}$, in the menopausal group, there were 22 patients (88\%) grade I, 2 patients $(8 \%)$ grade II, and 1 patient $(4 \%)$ grade III. Whereas in the premenopausal group there were 24 patients (96\%) grade I and 1 patient (4\%) patients with grade II meningioma. Our results are in accordance with the previous study by $\mathrm{Bi}$ et al. showing the prevalence of grade I, grade II, and grade III meningioma of 85 - 95\%, $5-10 \%$, and $1-5 \%$, respectively. ${ }^{15}$

Table 1 shows the distribution of BMI and body fat percentage in both study groups. The results showed 21 (84\%) patients in the menopausal group had a normal BMI compared to 16 (64\%) patients in the premenopausal group. As for the body fat percentage, as many as $19(76 \%)$ patients in the menopausal group were obese and had high body fat percentage compared to 14 (56\%) patients in the premenopausal group.

As we can see in Table 2, since the POR value was $>1$, it can be concluded that higher BMI in menopausal women resulted in a greater risk of 2.95 times for developing meningioma compared to menopausal women with normal BMI. From the PR calculation, menopausal women with overweight and obese BMI were 1.312 times more at risk of suffering from meningioma compared to premenopausal women having similar BMI. The confidence interval $(p=95 \%)$ for the true prevalence ratio was 0.934 1.84 .

As can be seen in Table 3, since the POR value was $>1$, it can be concluded that obese body fat percentage in menopausal women resulted in 2.49 times higher risk of developing meningioma compared to fat percentage. From PR calculation, menopausal women with obese body fat percentage are 1.36 times more at risk of suffering from meningioma compared to premenopausal women having similar body fat percentage. The confidence interval ( $\mathrm{p}=95 \%)$ for the true prevalence ratio was $0.901-2.051$.

\section{DISCUSSION}

The POR and PR values obtained in this study suggested that menopausal women who were overweight and obesity according to their BMI possessed a 2.95 times higher risk of developing meningioma compared to those menopausal women with normal BMI as well as an increased risk of developing meningioma by 1.312 times higher when compared with overweight and obese premenopausal women. The results of this study are consistent with the results of several previous cohort studies that showed a positive relationship between the risk of meningioma with higher BMI. ${ }^{3,5-8}$ High BMI plays important roles in oncogenesis through deviant regulation of sex hormone levels and insulin resistance, which are relevant to meningiomas. Michaud et al. ${ }^{4,8}$ reported an increased risk of meningioma by $48 \%$ among obese patients (BMI $\geq 30 \mathrm{~kg} / \mathrm{m}^{2}$ ) compared with patients having normal BMI (BMI 20-24.9 $\left.\mathrm{kg} / \mathrm{m}^{2}\right)^{15}$. Several menopausal women with normal body previous studies have also demonstrated an increased risk of meningioma by 40 $60 \%$ in patients with high BMI compared with low BMI. ${ }^{5,16}$

In addition to BMI, higher body fat percentage also increase the likelihood of developing meningioma as indicated in the menopausal group where those with high body fat percentage were 2.49 times more at risk of suffering from meningioma compared to menopausal women who average body fat percentage as well as having 1.36 times higher risk when compared with premenopausal women with obese body fat percentage. Body fat mass and adipose tissue are actively involved in endocrine function. Hence, higher body fat mass increases the production of estrogen hormone that subsequently affects the growth or progression of meningiomas. Similarly, higher levels of estrogen hormone in obese women can affect the growth of meningiomas. ${ }^{3,16-18}$ In addition, adipose tissue (fat cells) are also known to produce proinflammatory factors. In patients with obesity, there is an increase in the concentration of tumor necrosis factor (TNF)-alpha, interleukin (IL)-6 and C-reactive protein compared with a normal BMI. ${ }^{16,17}$

Johnson et al. ${ }^{6}$ found an association between menopausal women having high BMIandanincreasein the risk of developing breast cancer. This is not unexpected since higher BMI also affects sex hormone levels and/or insulin resistance, which may also be relevant to meningioma. ${ }^{6}$ In postmenopausal women where the ovaries are no longer functioning to produce estrogen hormone, extragonadal organs become the main source for estrogen production, particularly the adipose tissue. ${ }^{14}$ According to Robert Rutkowski $e t$ al. ${ }^{19} \mathrm{BMI}$ is only relevant to meningiomas during menopause. ${ }^{19,20}$

\section{CONCLUSION}

In postmenopausal women, high BMI and high body fat percentage increased the risk of developing meningioma for up to 1.3 times compared with premenopausal women with high BMI and body fat percentage and almost $2.5-3$ times higher risk compared with menopausal women with normal BMI and body fat percentage. 


\section{FUNDING}

No funding was received for this research.

\section{CONFLICTS OF INTEREST}

All authors have no conflict of interest.

\section{ETHICAL APPROVAL}

This research already has approved by the ethical committee of Dr. Hasan Sadikin Hospital Bandung with ethical approval number LB.02.01/X.6.5/338/2018

\section{AUTHORS' CONTRIBUTION}

CP participated in the reviewed the references, writing and design of the manuscript. RS and SO are reviewed and corrected the manuscript, participated in the discussion and results interpretation in this article. All authors read and approved the final version of the manuscript.

\section{REFERENCES:}

1. Moore BJ, Pi-Sunyer X. Epidemiology, etiology, and consequences of obesity. In: Akabas SR, Lederman SA, Moore BJ. (eds.) Textbook of obesity: Biological, physiological and cultural influence. New York: Wiley-Blackwell; 2012. p. $5-41$.

2. World Health Organization Western Pacific Region. The Asia-Pacific perspective: Redefining obesity and its treatment. Australia: WHO; 2000.

3. Wiedmann $M$, Brunborg C, Lindemann $\mathrm{K}$, Johannesen TB, Vatten L, Helseth E, Zwart JA. Body mass index and the risk of meningioma, glioma and schwannoma in a large prospective cohort study (The HUNT Study). Br J Cancer. 2013; 109(1): 289 - 294. https://doi.org/10.1038/ bjc. 2013.304
4. Sergentanis TN, Tsivgoulis G, Perlepe C, Ntanasis-Stathopoulos I, Tzanninis I-G, Sergentanis IN, Psaltopoulou T. Obesity and risk for brain/CNS tumors, gliomas and meningiomas: A meta-analysis. PLoS One. 2015; 10(9): e0136974. https://doi.org/10.1371/ journal.pone.0136974.

5. Jhawar BS, Fuchs CS, Colditz GA, Stampfer MJ. Sex steroid hormone exposures and risk for meningioma. J Neurosurg. 2003; 99(5): 848 853. https://doi.org/10.3171/jns.2003.99.5.0848.

6. Johnson DR, Olson JE, Vierkant RA, Hammack JE, Wang AH, Folsom AR, et al. Risk factors for meningioma in postmenopausal women: Results from the Iowa women's health study. Neuro Oncol. 2011; 13(9): 1011 - 1019. https://doi.org/10.1093/neuonc/nor081.

7. Benson VS, Pirie K, Green J, Casabonne D, Beral $\mathrm{V}$. Lifestyle factors and primary glioma and meningioma tumours in the million women study cohort. Br J Cancer. 2008; 99(1): 185 190. https://doi.org/10.1038/sj.bjc.6604445.

8. Michaud DS, Bove G, Gallo V, Schlehofer B, Tjonneland A, Olsen A, et al. Anthropometric measures, physical activity, and risk of glioma and meningioma in a large prospective cohort study. Cancer Prev Res. 2011; 4(9): 1385 - 1392. https://doi.org/10.1158/1940-6207.CAPR-110014.

9. Claus EB, Morrison AL. Epidemiology of meningioma. In: DeMonte F, Mc.Dermott MW, Al-Mefty O. (eds.) Al-Mefty's meningiomas $2^{\text {nd }}$ ed. New York: Thieme; 2011. p. 35 - 39.

10. Wiemels J, Wrensch M, Claus EB. Epidemiology and etiology of meningioma. J Neurooncol. 2010; 99(3): 307 - 314. https://doi.org.10.1007/ s11060-010-0386-3.

11. Barnholtz-Sloan JS, Kruchko C. Meningiomas: Causes and risk factors. Neurosurg Focus. 2007; 23(4): E2. https://doi.org/10.3171/FOC-07/10/ E2.

12. Simpson ER. Source of estrogen and their importance. J Steroid Biochem Mol Biol. 2003; 86(3 - 5): 225 - 230. https://doi.org/10.1016/ s0960-0760(03)00360-1.

13. Grantham JP, Henneberg M. The estrogen hypothesis of obesity. PLoS One. 2014; 9(6): e99776. $\quad$ https://doi.org/10.1371/journal. pone.0099776.

14. Green LE, Dinh TA, Smith RA. An estrogen model: The relationship between body mass index, menopausal status, estrogen replacement therapy, and breast cancer risk. Comput Math Methods Med. 2012; 2012: 792375. https://doi. org/10.1155/2012/792375.

15. Bi WL, Zhang M, Wu WW, Mei Y, Dunn IF. Meningioma genomics: Diagnostic, prognostic, and therapeutic applications. Front Surg. 2016; 3: 40. https://doi.org/10.3389/fsurg.2016.00040.

16. Rajaraman P. Hunting for the causes of meningioma - Obesity is a suspect. Cancer Prev Res. 2011; 4(9): 1353 - 1355. https://doi. org/10.1158/1940-6207.CAPR-11-0360.

17. Neidermaier T, Behrens G, Schmid D, Schlecht I, Fischer B, Leitzmann MF. Body mass index, physical activity, and risk of adult meningioma and glioma: A meta - analysis. Neurology. 2015; 85(15): 1342 - 1350. https://doi.org/10.1212/ WNL.0000000000002020.

18. Seliger C, Meier CR, Becker C, Jick SS, Proescholdt M, Bogdahn U, et al. Metabolic syndrome in relation to risk of meningioma. Oncotarget. 2017; 8(2): 2284 - 2292. https://doi. org/10.18632/oncotarget.13667.

19. Rutkowski R, Reszec J, Hermanowicz A, Chrzanowski R, Lyson T, Mariak Z, Chyczewski L. Correlation of leptin receptor expression with BMI in differential grades of human meningiomas. Oncol Lett. 2016; 11(4): 2515 2519. https://doi.org/10.3892/ol.2016.4272.

20. Qi Z-Y, Shao C, Huang Y-L, Hui G-Z, Zhou Y-X, Wang Z. Reproductive and exogenous hormone factors in relation to risk of meningioma in women: A meta-analysis. PLoS One. 2013; 8(12): e83261. https://doi.org/10.1371/journal. pone. 0083261 .

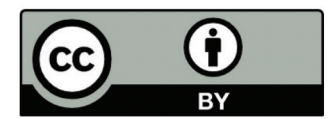

This work is licensed under a Creative Commons Attribution 